Virgínia Baglini Chiaravalloti 1 Maria Sílvia de Morais 2 Francisco Chiaravalloti Neto 2,3 Danaé Teresinha Conversani 4 Ana Maria Fiorin 3 Angelita Anália Carniel Barbosa 3 Amena Alcântara Ferraz 5

\section{Avaliação sobre a adesão às práticas preventivas do dengue: o caso de Catanduva, São Paulo, Brasil}

\author{
Evaluation of compliance with dengue \\ fever prevention: the case of Catanduva, \\ São Paulo, Brazil
}

1 Pontifícia Universidade Católica de São Paulo. Rua Pinheiro Guimarães 830 , São Paulo, SP

03141-030, Brasil.

2 Faculdade de Medicina de São José do Rio Preto.

Av. Brigadeiro Faria Lima 5416, São José do Rio Preto, SP 15090-000, Brasil.

fcneto@famerp.br

3 Superintendência

de Controle de Endemias.

Av. Philadelpho Manoel Gouveia Netto 3101 ,

São José do Rio Preto, SP 15060-040, Brasil.

4 Instituto de Saúde, Secretaria de Estado da Saúde de São Paulo. Rua Santo Antônio 590, São Paulo, SP 01314-000, Brasil.

5 Centro Universitário de Rio Preto. Rua Ivete Gabriel Atique 45,

São José do Rio Preto, SP 15025-040, Brasil.

\begin{abstract}
This paper presents the results of a qualitative survey on dengue fever prevention in an outlying neighborhood of Catanduva, São Paulo, Brazil. The research aimed to identify factors that interfere with on-going preventive practices by local residents. The authors began with a qualitative approach emphasizing preventive work within local women's daily context, mediated by the relationship they establish with vector control agents. The study indicates that to gain greater collaboration in dengue control requires: personalized consideration by both the programs and vector control agents, yet without excluding technical aspects; review of information content and communications methods: and training vector control agents to establish an on-going communications channel between the program and the population. Such factors can influence the population's interest in the prevention programs and minimize community discredit towards vector control activities.
\end{abstract}

Key words Dengue; Endemic Diseases; Vector Control; Community Participation

Resumo O artigo apresenta os resultados de pesquisa qualitativa sobre a prevenção do dengue, realizada num bairro periférico de Catanduva, São Paulo, Brasil, cujo objetivo foi identificar fatores que interferem na adesão das moradoras às práticas preventivas. Partimos de uma abordagem qualitativa, cujo foco da investigação foi pontuar o trabalho preventivo no contexto em que as mulheres vivem, mediado pela relação estabelecida com os agentes de controle de vetores. Identificamos que a conquista de um número maior de colaboradoras requer, entre outros aspectos, um olhar particularizado dos programas e dos agentes de controle de vetores, sem excluir procedimentos técnicos; a revisão do conteúdo e das formas de circulação das informações $e$ o estabelecimento de um canal de comunicação contínuo entre o serviço e a população. São aspectos que influenciam o interesse da população nos programas de prevenção e minimizam o descrédito do usuário em relação ao serviço.

Palavras-chave Dengue; Doenças Endêmicas; Controle de Vetores; Participação Comunitária 


\section{Introdução}

Vários estudos já demonstraram que o processo de incorporação das práticas preventivas pelas pessoas, não depende unicamente do grau de conhecimento sobre as formas de transmissão e prevenção do dengue. Esses estudos chegaram à conclusão de que o desenvolvimento de atividades rotineiras implica o aumento satisfatório do grau de conhecimento, mas o mesmo não acontece com relação à mudança de práticas preventivas para a eliminação total dos criadouros (Chiaravalloti Neto et al., 1998; Gratz, 1993; Leontisini et al., 1993; Rosenbaum et al., 1995; Swaddiwudhipong et al., 1992). Fatores como descrédito da população nos serviços de saúde, falta de interesse em participar das atividades preventivas, crença no caráter inevitável da doença, repasse verticalizado do conhecimento (Clark, 1995; Nathan, 1993) e a solicitação dos órgãos de saúde de execução de medidas restritas ao comportamento individual (Oliveira \& Valla, 2001) interferem na adesão das pessoas aos programas de prevenção.

Observando o modelo aplicado no Estado de São Paulo, onde identificamos vários dos aspectos apontados, coloca-se o imperativo de desenvolver ações que incluam estudos sobre os fatores sócio-culturais de uma comunidade, seus valores, experiências e crenças relacionados à doença, seu controle e prevenção. A incorporação dessas informações pelos programas disponibilizaria um leque de medidas mais efetivas, envolvendo as comunidades em ações que estejam ao seu alcance, capacitando-as a exigir dos órgãos públicos uma atuação para além da adoção de medidas preventivas restritas a uma única endemia, rompendo com a forma fragmentada como são tratadas as questões de saúde e ambiente.

Em Catanduva, município localizado na região noroeste do Estado de São Paulo, os órgãos de saúde utilizam várias abordagens para equacionar o problema da transmissão do dengue, como a realização de campanhas educativas por meio dos veículos de comunicação de massa, o controle de vetores pela eliminação de criadouros da forma larvária do Aedes aegypti e a aplicação de inseticidas para a eliminação das formas imaturas e adultas desse mosquito. Entretanto, observa-se a manutenção de criadouros nas residências e de níveis elevados de infestação do vetor, além do risco de transmissão da doença. Com o objetivo de identificar fatores que interferem na adesão total das moradoras do Solo Sagrado, bairro periférico do município, às medidas preventivas, realizamos uma pesquisa qualitativa, cujos resultados apresentamos neste artigo.

\section{Abordagem do problema}

Para compreender o processo pelo qual as pessoas constróem o conhecimento e dão significado à prevenção do dengue, partimos do entendimento de que a vida cotidiana “(...) apresenta-se como uma realidade interpretada pelos homens e subjetivamente dotada de sentido para eles na medida em que forma um mundo coerente. O mundo da vida cotidiana não somente é tomado como uma realidade certa pelos membros ordinários da sociedade na conduta subjetivamente dotada de sentido que imprimem em suas vidas, mas é um mundo que se origina no pensamento e na ação dos homens comuns, sendo afirmado como real por eles" (Berger \& Luckmann, 1985:35-36). As práticas cotidianas constituem-se em experiências com diferentes significações, sendo a linguagem o meio pelo qual as pessoas constróem suas interpretações, descrevem, explicam e objetivam os significados sobre os fenômenos que estão a sua volta. Entendida como prática social, a linguagem traduz a ação e o posicionamento das pessoas no mundo. É nessa teia de relações humanas, onde interagem atores com diferentes saberes e experiências, que ocorre o processo de construção do conhecimento e do significado do trabalho de prevenção.

O conhecimento sobre a doença e as informações sobre os procedimentos de controle e prevenção do dengue são repassados às comunidades por meio da mídia de massa e dos discursos, valores e experiências dos profissionais de saúde que fazem a intermediação entre serviço e usuário. Esse conjunto de informações constitui-se num dos principais fundamentos sobre os quais as pessoas constróem o conhecimento e dão significado ao trabalho de prevenção do dengue. Entretanto, autores chamam a atenção para a pouca efetividade dos programas de prevenção por não reconhecer as prioridades, não proporcionar incentivo à participação da comunidade na busca de soluções (Stotz, 1993), e desconsiderar a construção compartilhada do conhecimento a partir do saber científico e popular (Oliveira \& Valla, 2001). Um exemplo é a condução de campanhas preventivas que, muitas vezes, responsabilizam as pessoas pela ausência de participação e não adesão à prevenção, num processo denominado por Valla (1993) de ditadura da urgência, quando as autoridades tentam conter as epidemias com programas emergenciais com a execução de procedimentos de responsabilidade da população.

Stotz (1993), identifica nesses programas uma lógica de responsabilização do indivíduo 
sobre sua ação, e por isso apresentam um caráter individualizante, parcial e corretivo diante de questões que requerem uma abordagem social e holística. Explica o autor, “(...) a força desse tipo de abordagem é tanto maior quanto mais rígida se torna na sociedade e, por conseqüência, no sistema institucional de saúde a noção de responsabilidade individual dos cidadãos em contrapartida à da cidadania coletiva e dos direitos sociais" (Stotz, 1993:21). Questionamos assim, a contribuição dos programas para tornar efetiva a prevenção do dengue, pois no âmbito da educação e saúde predomina o enfoque preventivo, baseado no modelo médico de associação entre padrões comportamentais e de doença, em que se persegue a mudança de comportamentos por estilos de vida mais saudáveis. Depreende-se que um modelo baseado unicamente na divulgação maciça dos procedimentos de prevenção não alcança mudanças no hábito. Isso porque se define um nível de conhecimento como ideal e supõe-se que o seu repasse à população irá resultar na eliminação total dos criadouros, num processo em que a interlocução entre usuário e serviço está excluída.

\section{O caso de Catanduva}

Estudo quantitativo realizado em 1999 a partir de uma amostra aleatória de 225 domicílios, de um total de 1.524, do Solo Sagrado, bairro de baixa renda do Município de Catanduva, no qual foram entrevistadas mulheres moradoras dos domicílios sorteados, revelou que $8 \%$ delas não sabiam ler e escrever; $66 \%$ tinham o 1 o grau incompleto e $26 \%$ o 1 o grau completo ou mais. Das entrevistadas, $22 \%$ tinham entre 13 e 29 anos de idade, $32 \%$ entre 30 e 39 anos, $20 \%$ entre 40 e 49 e $26 \%$ com 50 anos ou mais. Em $11 \%$ das residências das entrevistadas não foram encontrados criadouros do mosquito do dengue, em $33 \%$ foram encontrados entre $1 \mathrm{e}$ 3 , em $35 \%$ entre 4 e 10 e em $21 \% 11$ ou mais criadouros. O estudo indicou que, apesar do conjunto das mulheres ter informação correta sobre criadouros de A. aegypti e sua prevenção, ou antes, reproduzir em seu discurso as informações que foram repassadas, a grande maioria fez apenas parte das associações necessárias entre conhecimento e práticas (Chiaravalloti-Neto et al., dados não publicados).

Diante desse cenário, investigamos a experiência de um grupo de mulheres, cujo foco foi pontuar a prevenção do dengue na realidade em que elas vivem, tendo como pano de fundo o modelo preventivo preconizado pelo serviço de saúde e a experiência que elas têm com os agentes de controle de vetores. Ao trabalhar com um grupo reduzido de pessoas, asseguramos a representatividade da fala individual mantendo a possibilidade de generalizar aspectos singulares, pela semelhança das condições sociais de existência. Aspecto já discutido por Bourdieu (1993), no conceito de habitus, como um sistema de disposições duráveis e intransferíveis que integra todas as experiências passadas ou como uma matriz de preocupações, de percepções, de apreciações e ações. As falas das mulheres são entendidas como linguagem em ação (Spink \& Medrado, 1999), por meio da qual produzem significados e buscam se posicionar diante das trocas e relações entre as pessoas numa determinada realidade. Essa abordagem nos aproximou da perspectiva das mulheres quanto às formas de acesso às informações e de interlocução com os agentes de controle de vetores, e dos possíveis conflitos que daí emergem. Essa trajetória vincula-se às metodologias qualitativas, entendidas como “aquelas capazes e incorporar a questão do significado e da intencionalidade como inerentes aos atos, às relações, e às estruturas sociais" (Minayo, 1996:30). A escolha desse método parte de histórias individuais, para em seguida extrair uma história social ou estudar uma realidade coletiva por meio de fatos singulares.

A pesquisa ocorreu entre os meses de maio e agosto de 2000, quando entrevistamos dezesseis moradoras do bairro Solo Sagrado. Na escolha dessas entrevistadas, levou-se em conta a faixa etária, a escolaridade e o número de criadouros existentes em suas casas, sendo sua distribuição proporcional às freqüências dessas variáveis obtidas no estudo já citado, ancorando o grupo em uma estratificação representativa da população. No processo de investigação, foi elaborado um roteiro de entrevista, testado previamente, que abordou a percepção das mulheres quanto às formas de transmissão do dengue e a gravidade da doença, a relação entre elas e os agentes de controle, suas opiniões e sugestões sobre as ações desenvolvidas pelo serviço no bairro. Com base nesse roteiro realizamos entrevistas semi-estruturadas, por se tratar de um instrumento privilegiado tanto para captar o ponto de vista dos atores envolvidos na realidade estudada, como para apreender as relações sociais nas quais as representações, os comportamentos, os saberes e os modos de vida são produzidos. Na organização dos resultados, partimos da análise dos temas identificados nos depoimentos, a partir dos quais obtivemos posicionamentos que permitiram verificar a correlação entre as ações dos 
agentes e as práticas preventivas das mulheres, e identificar fatores que limitam a sua adesão à prevenção. Realizaram as entrevistas, as duas primeiras autoras deste artigo que tinham envolvimento prévio com a população e participado do estudo quantitativo anterior, o que facilitou a relação entre as pesquisadoras e as mulheres.

\section{Resultados e discussão}

\section{A disseminação de mosquitos \\ e a transmissão do dengue}

Na percepção das mulheres, a transmissão do dengue está associada à presença de mosquitos e outros insetos contaminados, e não unicamente ao A. aegypti. Elas se preocupam com os ambientes favoráveis à disseminação desses agentes, como casas fechadas e abandonadas, praças, terrenos baldios, riachos e rios, sem fiscalização da prefeitura, e freqüentemente utilizados para jogar objetos associados a entulho e lixo. Reivindicam das autoridades uma fiscalização efetiva no trato desses espaços, o que evidencia a presença de uma contradição entre o discurso e a prática preventiva oficiais, como ilustram os trechos a seguir: "Ver os terrenos vazios, matos, mandar carpir, cobrar impostos ou fazer alguma coisa, ou então cobrar da água ou da força pra eles não fazerem mais isso aqui ..., tem tanto terreno vazio, cheio de entulhos, porcarias... então eu acho que se eles viessem seria bom"; e “... eu acho que uma vistoria nesses terrenos baldios sabe,... que a prefeitura faça esse muro e cobre, dificulta, tem que dificultar pro pessoal jogar sujeira... e fazer uma limpeza periódica...”. Da mesma forma, a sujeira e o lixo preocupam as mulheres: "Se é grave ou não é, pode ser doença grave, se há um criadouro de mosquito que junte mosca, entendeu, qualquer machucadinho que alguma mosca senta, porque lixo junta". A proximidade com esses ambientes gera receio nas moradoras agravado pelo efeito surpresa com que a transmissão da doença pode ocorrer: “(...) eu cuido muito, a gente tem medo... é o problema da transmissão da doença, que sei lá, a gente sem esperar pode acontecer, tendo o criadouro do mosquito pode acontecer de picar alguém e a gente não ver $e$ não perceber e de repente a coisa começa a complicar".

As omissões do poder público podem instaurar uma relação de descrédito por parte do usuário e aumentar o seu desinteresse nos programas de prevenção. Clark (1995:S9), explica que “(...) a desconfiança face os representantes do governo, por experiências negativas prévias, pode reduzir o interesse por participar no programa”. Para Giddens (1991:87), esse desinteresse guarda relação com “(...) a natureza das instituições modernas [que] está profundamente ligada ao mecanismo da confiança em sistemas abstratos, especialmente a confiança em peritos". Nesse caso, o trabalho preventivo pode ser associado a um sistema abstrato, pois consiste num conjunto de conhecimentos e de procedimentos utilizados no combate à disseminação de criadouros e de mosquitos. Seus representantes diretos - os agentes de controle de vetores - são por excelência portadores de um conhecimento especializado, e por isso, proporcionam maior segurança às pessoas - a própria prevenção - nas suas atividades do diaa-dia. $\mathrm{O}$ autor esclarece que todo sistema abstrato estabelece um compromisso com os atores leigos, e estes lhes conferem uma dose de confiança, dirigida precisamente aos seus representantes que será renovada, ou não, a depender da postura destes últimos diante dos atores envolvidos. No trabalho preventivo, a contradição entre discurso e prática oficiais, identificada pelas entrevistadas, torna vulnerável o ponto de interseção entre sistema abstrato e os atores leigos e provoca o desinteresse da comunidade no trabalho preventivo. É possível reconhecer esse descompasso na atuação do poder público, à medida em que estabelece um modelo normativo de prevenção sem a correspondente capacidade de cumpri-lo. Esses fatores vão interferir sensivelmente no processo de construção do significado do trabalho preventivo.

\section{A construção do significado \\ da prática preventiva}

Pedimos para que as mulheres relatassem a rotina de trabalho dos agentes de controle de vetores, no período anterior ao de realização das entrevistas. Elas destacaram as seguintes atividades: visitação nas casas, fiscalização, vistoria, aconselhamento e orientação, retirada do lixo, doação de sacos de lixo e colocação do larvicida nas plantas. Conforme as entrevistadas, os agentes ainda chamam a atenção para os cuidados com os criadouros e alertam para o cuidado com o acúmulo de entulho, associado a objetos variados e sem utilidade. A minuciosidade associada ao caráter vistor do trabalho dos agentes foi mencionada em alguns depoimentos: "Ah, eles olham dentro da casa da gente, até dentro da casa mesmo pra ver se tem vaso de flor, coloca aquelas coisinhas nas plantas, nos vasos, eles olham em tudo, caso tiver algu- 
ma coisa eles limpam o lugar, avisa a gente que não pode deixar desse jeito, ensina a gente bastante coisas"; e “(...) eles vêm vê sempre, põem aqueles venenos, mesmo que tem terra nos pratos assim, eles passam os venenos, as moças vê mesmo, essas moças que vêm vê, revista tudo, $e$ ainda elas falam 'ainda bem que na casa da senhora é tudo em ordem', e eu falo, é porque eu tenho medo, a gente já tem uma luta de doença que não é fácil e ainda se acontecer essas coisa é pior (...)". As entrevistadas não qualificaram de imediato esse conjunto de procedimentos como um programa preventivo, apesar de confirmarem a presença freqüente de agentes que realizam tais atividades.

A preocupação reiterada das entrevistadas em manter a casa "livre do mosquito", permite afirmar que elas incorporaram a prevenção, mesmo sem identificá-la como tal, associandoa à limpeza da casa, quando efetuam os cuidados com os criadouros. Trechos de depoimentos ilustram essa prática: “(...) o trabalho é normal, porque se tem que ter higiene dentro da sua casa, já faz parte, se vai deixar poça d'água, lixo, acho que infelizmente tem que ser dito, mas nem precisava dessas orientações (...)"; "Porque o meu dia é tudo normal, cuidar de planta, de casa, dos filhos, deixar tudo em ordem, limpar (...)"; e "Se eu vou limpar debaixo da pia, das garrafas, eu gosto de por do meu modo pra não ter problema, se é das minhas plantas, então, sou eu quem faço"; “(...) a minha casa é assim humilde, mas eu gosto de tudo certinho, tudo no lugar, tudo ajeitadinho. Não tem como falar pra você que eu prefiro que ele faça pra mim, porque não tem nada".

Apesar do cuidado com os criadouros estar integrado à limpeza diária da casa, algumas mulheres relataram que sempre "escapa alguma coisinha”, e nesse caso a falta de tempo para cuidar dos criadouros requer a presença constante dos agentes: “(..) se bem que o tempo é assim, eu tenho que fazer do jeito que dá, porque outro dia ficou um mato aí, ficou aí uns dez dias, que ele carpiu pra fazer essa horta, nossa que vergonha, deixei juntar todos esses dias". Outras entrevistadas comentaram: “ $A h$, eu não sei, às vezes a gente pensa que alguma coisinha que não tem nada a ver, e eles vêem"; e “(...) eu trabalho fora, sempre passa alguma coisinha, se as moças passam, acham alguma coisa, tem que voltar ou marcar pra conversar com as pessoas, pra evitar esse tipo de problema". Quanto ao cumprimento das recomendações feitas pelos agentes, chamou a atenção que uma das entrevistadas relatou certa dificuldade de entendimento: "Entender é difícil no começo, é duro. A gente não está acostumado com aquilo, a gente procura entender, pensa, mas acaba entendendo (...) que é coisa do dia a dia é e meio difícil, mas a gente cumpri".

Para as mulheres, o cuidado com os criadouros vem antes associado à higienização do ambiente doméstico, como garantia de imunidade às suas casas, e não diretamente ao trabalho de prevenção. O relato constante de que "criadouros do Aedes, na minha casa não tem" demonstra que as mulheres atestam que suas casas não são ambientes favoráveis ao mosquito, dada à prática invariável do cuidado e da limpeza, como ilustram alguns trechos de entrevistas: "Eu acho que o cuidado tem que vim da gente, eu prefiro, eu acho que eu não posso criar uma coisa e depender dos funcionários pra vim cuidar"; e “(...) não adianta limpar aqui, sendo que ali, tem um criadouro, de lá vem prá ca e cria bicho, e é anti-higiênico também".

A presença do entulho assume importância ainda maior no contexto da prevenção do dengue, sendo associado à sujeira, à falta de higiene e de cuidado com a casa, caracterizando um ambiente propício à disseminação de mosquitos. Como receiam algumas entrevistadas, isso resulta num estigma para a própria casa. Como um procedimento de eliminação de mosquitos e doenças e no combate a ambientes insalubres, a higienização é uma referência para qualificar o espaço do outro, e não apenas um conjunto de cuidados com a casa e com os criadouros. Em vários depoimentos, o vizinho teve o seu quintal ou a sua casa associados a focos de disseminação de mosquitos e de transmissão do dengue. Ilustram essa observação os seguintes depoimentos: “Ah, eu conheço, (...) aqui que eu falo é nessa casinha [aponta], porque já foi encontrado, o pessoal vem, joga lixo, sempre tem gente aí, joga entulho, eu acho que deve ter sim (...)”; “(...) a única casa que parece ter sujeira é aquela ali adiante [aponta], tem muita tranqueira no quintal, pode até ter uma vasilha com água parada”; e “(...) porque se eu cuido pra não ter, se alguém não cuidar ... tendo no vizinho, transmite pra mim". O incômodo da denúncia está ilustrado no seguinte trecho: “Às vezes eu não sei, mas o outro vizinho de lá [aponta] sabe mais ou menos quem é, e pra gente dedar fica chato, então se cada um tiver junto, cada um se toca, um olha pro outro e já sabe que é duro condenar, e falar foi fulano".

Geralmente, a denúncia resulta da presença de entulho em algumas casas e pela ocorrência de recusas ou maus tratos de alguns moradores com os agentes. Esse aspecto, já discutido por Valla (1993), implica a culpabilização da vítima. É um dos efeitos mais perniciosos do mau funcionamento dos serviços públicos 
no Brasil, e demonstra a falta de compromisso dos governos que delegam à população a responsabilidade da prevenção. A culpabilização consiste na individualização da questão por parte dos governos no combate aos vetores, e “(...) o culpado direto pela doença seria o mosquito transmissor e o indireto, a população; se a população vier a contrair a doença, será por não ter seguido corretamente os conselhos de prevenção e combate ao mosquito" (Valla, 1998: 9). Em nossa pesquisa essa lógica, característica dos serviços de saúde, encontra-se "disseminada" entre a vizinhança.

Associada a essa questão está a ênfase dada pelas mulheres ao saber técnico em detrimento do conhecimento que as pessoas têm sobre controle e prevenção do dengue. O baixo grau de escolaridade e o poder aquisitivo são fatores que, na perspectiva das mulheres, interferem na prática preventiva, como ilustram as seguintes falas: "Ah, eu acho que em todo lugar tem, que nem eu cuido da minha casa, a vizinha cuida, a outra cuida, mas ali a gente vê que a casa é mais humilde, então você pode chegar lá e constatar, tem um monte de papelão..."; "Nas casas que o pessoal não cuida, a gente procura cuidar, mas não é todo mundo que tem instrução, que colabora.... porque você vê, tem gente que guarda entulho... acho que teria que pegar mais esse povo desinformado, esse povo que ofende o pessoal..., no caso dar orientação, aqueles que foram maltratados, vir outro funcionário, ou com maior grau, porque infelizmente hoje é assim, o pessoal só obedece, só trata bem aquele que vem engravatado"; e "Devia ter uma pessoa já mais chefe, mais cabeça e marcar uma reunião no bairro,... então ali na hora vai tá explicando pra todos, então cada um dá uma opinião, não é?". Alega-se que, mediante tais condições, essas pessoas estariam contribuindo para o aumento de criadouros no bairro. Valla (1998:10), explica que a população mais humilde sofre com o estigma construído em torno das condições de vida da população trabalhadora, tal como "família pobre é igual à doença”, pois enquanto o saber popular é desqualificado, predomina como parâmetro o saber formal, o grau de escolaridade e o saber técnico. O depoimento a seguir ilustra estes aspectos: “(...) porque tem coisa aqui que eu não sei, é claro, vocês sabem melhor, tão estudando, tão vendo, então é uma coisa de às vezes vocêfazer um remédio em casa e não vale nada, e se vai no médico e ele dá outro, é pá sará. Então, é a força das pessoas de mais classe, de mais estudo, de mais trabalho, que nem vocês, chega, explicar e a gente fazer". Levando em conta que, na área estudada, as condições de vida da po- pulação, o perfil sócio-econômico e o grau de escolaridade são equilibrados, esses fatores isolados não têm o poder de homogeneizar a percepção das pessoas sobre os espaços favoráveis à disseminação de criadouros e mosquitos. A percepção é mediada também pela idade, tipo de trabalho que a pessoa desenvolve, as relações que estabelece no seu cotidiano e todo o repertório adquirido por meio dos programas e dos agentes de controle de vetores. Portanto, se um membro da família freqüenta algum lugar que desenvolve prevenção, como um órgão público ou escolas, isso vai influenciar a sua percepção e o conhecimento adquirido sobre a doença e sua prevenção.

\section{Práticas preventivas:}

o que as mulheres sugerem

Ao opinarem sobre as ações desenvolvidas no bairro e a atuação dos agentes, as entrevistadas fizeram uma série de sugestões que estão na pauta de discussão sobre controle e prevenção do dengue, como: a relação entre espaço público e privado (ambiente doméstico), a confiança e o vínculo entre usuário e serviço, a demanda por formas mais acessíveis de apreensão das informações.

Apesar das mulheres serem receptivas à visita domiciliar, destacou-se uma importante queixa: a ausência de vínculo entre serviço e usuário, dada pelo rodízio de agentes, o que prejudica o andamento do trabalho, como explicou uma das entrevistadas: “(...) o cara já passou uma vez, passa duas vezes, passa a terceira vez, a pessoa adquire uma certa confiança, uma certa amizade. Porque eles trocam sempre o pessoal, cada dia passa um, então não dei$x a$, com essa violência que tem aí fora, o pessoal tem medo de deixar entrar". Surgiram críticas dirigidas ao serviço, quando este deveria estar pronto a atender demandas do bairro, e também aquelas particulares, nem sempre explicitadas pelas moradoras na ocasião das visitas. Uma das entrevistadas falou da necessidade do agente conhecer melhor a comunidade em que atua para não interferir no dia-a-dia das moradoras: “(...) o trabalho educativo não tem nada de errado mas (...) só é ruim quando você tá dormindo, você tá ocupado e chega batendo (...) chega em uma hora que você não pode atender".

Para minimizar os problemas decorrentes da falta de interação tanto entre serviço e usuário, como entre vizinhança, uma das entrevistadas sugeriu a presença de um mediador: "Eu acho que tem que dá um pouquinho mais de atenção e ter um presidente de bairro. Eu acho que tem que ter... pra facilitar o trabalho dessas 
pessoas (...)". Também foi reclamada a instauração de um espaço de "solidariedade" no bairro, onde as pessoas pudessem conversar sobre os problemas do dengue, entre outros. Essa prática poderia romper com a relação de denúncia entre vizinhança e rever o caráter vistor do trabalho preventivo: "As pessoas se ajudar uma a outra, eu acho bom eles vim, orientar todo mundo, a gente estar sempre participando, pra que não ocorra na minha casa, na casa do vizinho, então eu acho que numa comunidade é sempre bom um ajudar o outro".

Ao mesmo tempo em que as mulheres reclamam por um vínculo mais estreito com os agentes, também estabelecem uma linha divisória nítida entre o trabalho que desempenham em suas casas e o trabalho dos agentes. Elas preferem realizar o "serviço de acabar com os criadouros", e aos agentes caberia orientá-las: “Eu prefiro eu cuidar das minhas coisas. Eu já sei como que é, então eu cuido direitinho pra não ter nada de errado e não acontecer nada,(...) eu não gosto que ninguém faça por mim porque eu gosto do meu jeito. Me orientar sempre, eu gosto que eles me orientem, como a gente tem que fazer, então isso daí eu concordo, mas eu fazendo, eles me orientam e eu faço"; "Na minha casa eu mesma faço. Ah!, sei lá, porque às vezes eles não fazem do jeito que a gente quer fazer"; e "(...) a gente tem que cuidar do que é da gente". Orientar sobre o uso do larvicida na casa e nas plantas, é um bom exemplo apontado pelas mulheres do que compete aos agentes realizar: "Dependendo da casa, eles têm que explicar melhor, não só pôr o veneno, e dar o folhetinho e ir embora"; e "(...) instruir a população, instruir, chegar e conversar, instruir; o importante é eles instruírem, não chegar, passar aquele veneninho nas plantas e ah! tudo bem aqui". O larvicida pode constituir-se num fator de inibição à adesão, pois algumas entrevistadas questionaram que se, por um lado, é problemático deixar um prato com água debaixo das plantas, assim como alertam os programas de prevenção, por outro, não se sentem totalmente seguras e informadas quanto ao prejuízo que o larvicida pode causar às suas plantas, como ilustram os seguintes depoimentos: “(...) porque às vezes o pessoal tem medo disso, eu já vi casas que a pessoa não deixa entrar, porque eles vão por aquele negócio que depois mata as plantas, eu já perdi dois, três vasos" e “Ah, eu acho que eles tacam esse pozinho nas plantas, pra mim, eu acho que isso não tem nada a ver". Reiterando a preferência das mulheres em executar os cuidados com os criadouros, algumas gostariam de aplicar o larvicida por conta própria: “(...) a gente não tem esse veneno, deveria ter pra comprar, a gente não tem, eu não acho ruim que coloca”. Há quem concorde com a execução do serviço: "Eu quero que eu mesma cuido, mas se passar uma pessoa pra modo de passa um veneno nas plantas, eu gosto disso". No caso em que o uso do larvicida é controverso, seria necessário que os agentes apresentassem às moradoras alternativas de eliminação de criadouros e mosquitos A. aegypti, utilizando soluções caseiras como o sal de cozinha ou a água sanitária, ficando a moradora assegurada de cuidar ela própria de sua casa conforme critérios já estabelecidos.

Segundo algumas mulheres, o repasse do conhecimento, o conteúdo e as formas de veiculação das informações foram classificados como exaustivos: "Ah, é tanto que eles falam que já era suficiente pra entrar na cabecinha de cada um”; “(...) nessa campanha, instruir com panfleto, sei lá, se bem que panfleto o pessoal nem lê, alguns lêem, outros não; e “(...) elas explicam, deixam o folhetinho que a gente tá cansada de vê (...) e eles deixaram um folhetinho, nem sei onde tá, porque eu vou guardando sabe, mas já faz uns dois meses isso". Essa prática banaliza as medidas de prevenção no simples repasse do conhecimento, provoca a saturação do conteúdo informativo e reduz a rede de colaboradoras no bairro.

Diante das demandas, sugestões e críticas apresentadas nas entrevistas, observa-se um encadeamento de questões que, mesmo sendo particulares porque pertencem ao universo de um grupo específico de mulheres, indicam uma possível conduta, senão para os programas de um modo geral, mas para as localidades que apresentem características similares às do bairro estudado. Também permitem observar uma matriz de práticas das moradoras, que é a sua preferência em realizar o trabalho da prevenção, mesmo reconhecendo ser necessário reforçar o vínculo com o agente. $\mathrm{O}$ que parece ser contraditório, traduz a necessidade de uma relação de confiança fundada na valorização do conhecimento dessas mulheres; requer uma percepção de que existem formas de pensar e modos de apreensão da realidade diferentes, além da revisão das formas de repasse do conhecimento, pois, muitas vezes, o discurso técnico não alcança o seu principal interlocutor. Assim, a principal demanda colocada pelas mulheres está na busca de uma nova relação entre agentes e população, cabendo ao agente o papel de orientador e não mais de fiscalizador.

Conciliar esses aspectos é o desafio dos programas de controle. Valla (1993:74), explica: “(...) não basta convocar a população a participar dos serviços. É indispensável considerar a 
visão de mundo e o comportamento das camadas populares quando entram em relação com os técnicos dos serviços de saúde. Na medida em que se coloca a participação popular situa-se, também, a possibilidade de conflitos com técnicos do setor". Há que se conhecer a realidade em que se quer atuar; privilegiar a atuação conjunta entre usuário e serviço, em que sejam sinalizadas pela própria comunidade as suas potencialidades, deficiências e dificuldades no contexto da prevenção, manter uma atuação efetiva dos serviços de prevenção como forma de estabelecer um compromisso com as pessoas e garantir a confiança necessária para que os agentes atuem no espaço privado das moradoras - a casa. Essa medida requer a construção compartilhada do conhecimento a partir do saber científico e popular e a administração dos conflitos que daí emergem (Oliveira \& Valla, 2001).

\section{Conclusão}

A prevenção do dengue implica o lidar com a necessidade permanente de combater os criadouros de A. aegypti, o que depende da adesão da comunidade às propostas de prevenção e do significado que elas alcançam para as pessoas. Alguns fatores que interferem nesse processo: a contradição entre o discurso e a prática preventiva oficiais identificada pelas próprias moradoras, a ausência de interação entre a população e o serviço, e a desconsideração do saber popular sobre a prevenção, construído na vivência do bairro.

$\mathrm{Na}$ relação serviço/usuário, as mulheres preferem cuidar elas próprias dos criadouros no âmbito da casa, apesar de reclamarem por uma abordagem mais particularizada por parte dos agentes. O uso do larvicida é exemplar, pois chama a atenção para a necessidade dos programas respeitarem as demandas das moradoras em relação à aceitação ou não dos procedimentos de prevenção, além de ampliar o leque de alternativas no combate ao dengue. Ao serviço caberia uma atuação efetiva no cuidado com os espaços públicos, pois a presença constante de criadouros nestes locais, associada à possibilidade de ocorrência da doença, geram receio e medo nas moradoras, e até situações de denúncias entre vizinhos. Essa reação individualiza o problema do dengue, inibe o potencial de participação das pessoas e interfere na adesão às medidas preventivas. A atuação do serviço nesse sentido poderia fortalecer a relação de compromisso com o usuário, ampliando a rede de colaboradoras.

No grupo de pessoas entrevistadas, a transmissão do dengue não foi associada unicamente à presença do A. aegypti e de recipientes com água propícios à sua disseminação, mas a qualquer mosquito ou inseto contaminado que se dissemine em ambientes insalubres, caracterizados pelas mulheres pela presença de entulho, sujeira e falta de higiene. No contexto da prevenção, estes são aspectos incompatíveis com a representação construída pelas mulheres sobre o espaço doméstico - ambiente sadio, limpo e pouco favorável à existência de criadouros e à disseminação de mosquitos e insetos. Justifica-se a fala das mulheres de que nas suas casas não existem criadouros do mosquito, mantendo-se a contradição com a realidade observada, isto é, a presença de locais para a sua disseminação.

Os aspectos identificados na pesquisa convergem para a revisão do conteúdo dos programas e do modo de transmitir o conhecimento, levando em conta o processo de interpretação da informação por parte do receptor. Daí a necessidade em se resgatar e valorizar o conhecimento das moradoras, adequar a linguagem técnica ao seu dia-a-dia de forma que o discurso oficial não se sobreponha à sua fala. Talvez se consiga, senão romper, reduzir o descompasso entre o discurso e a prática preventiva oficiais e alcançar índices mais satisfatórios de adesão.

\section{Agradecimentos}

Os autores agradecem à Organização Pan-Americana da Saúde e à Fundação Nacional de Saúde pelo financiamento do projeto, e às mulheres do bairro Solo Sagrado, Município de Catanduva, que participaram das entrevistas. 


\section{Referências}

BERGER, P. \& LUCKMANN, T., 1985. Os fundamentos do conhecimento na vida cotidiana. In: A Construção Social da Realidade (P. Berger \& T. Luckmann, org.), pp. 35-68, Petrópolis: Editora Vozes.

BOURDIEU, P., 1993. A procura de uma sociologia prática. In: Sociologia (R. Ortiz, org.), pp. 7-81, São Paulo: Ática.

CHIARAVALLOTI NETO, F.; MORAIS, M. S. \& FERNANDES, M. A., 1998. Avaliação dos resultados de atividades de incentivo à participação da comunidade do Município de São José do Rio Preto, São Paulo, e da relação entre conhecimentos e práticas desta população. Cadernos de Saúde Pública, 14(Sup. 2):101-109.

CLARK, G. G., 1995. Situación epidemiológica del dengue en América. Desafíos para su vigilancia y control. Salud Pública de México, 37:S5-S11.

GIDDENS, A., 1991. As Conseqüências da Modernidade. São Paulo: Unesp.

GRATZ, N. G., 1993. Lessons of Aedes aegypti control in Thailand. Medical and Veterinary Entomology, 7:1-10.

LEONTISINI, E.; GIL, E.; KENDDALL, C. \& CLARCK, G. G., 1993. Effect of a community-basead Aedes aegypti control programme on mosquito larval production sities in El Progresso, Honduras. Transactions of the Royal Society of Tropical Medicine and Hygiene, 87:267-271.

MINAYO. M. C. S., 1996. O Desafio do Conhecimento. Pesquisa Qualitativa em Saúde. São Paulo: Editora Hucitec/Rio de Janeiro: ABRASCO.

NATHAN, M. B., 1993. Critical review of Aedes aegypti control programs in the Caribbean and selected neighboring countries. Journal of the American Mosquito Control Association, 9:1-7.

OLIVEIRA, R. M. \& VALLA, V. V., 2001. As condições e as experiências de vida de grupos populares no Rio de Janeiro: Repensando a mobilização popular no controle do dengue. Cadernos de Saúde Pública, 17(Sup.):77-88.
ROSENBAUM, J.; NATHAN, M. B.; RAGOONANANSIRGH, R.; RAWLINS, S.; GAYLE, C. CHADEE, D. D. \& LLOYD, L. S., 1995. Community participation in dengue prevention and control: A survey of knowledge, attitudes and practice in Trinidade and Tobago. American Journal of Tropical Medicine and Hygiene, 53:111-117.

SPINK, M. J. \& MEDRADO, B., 1999. Produção de sentidos no cotidiano: Uma abordagem teóricometodológica para análise das práticas discursivas. In: Práticas Discursivas e Produção de Sentidos no Cotidiano (M. J. Spink, org.), pp. 41-61, São Paulo: Editora Cortez.

STOTZ, E. N., 1993. Enfoques sobre educação e saúde. In: Participação Popular, Educação e Saúde, Teoria e Prática (V. V. Valla \& E. N. Stotz, org.), pp. 11-22, Rio de Janeiro: Relume-Dumará.

SWADDIWUDHIPONG, W.; CHAOVAKIRATIPONG, C.; HGUNTRA, P.; KOONCHOTE, S.; KHUMKLAM, P. \& LERDLUKANAVONGE, P., 1992. Effect of health education on community participation in control of dengue hemorrhagic fever in an urban area of Thailand. Southeast Asian Journal of Tropical Medicine and Public Health, 23:200-206.

VALLA, V. V., 1993. Participação popular e saúde: A questão da capacitação técnica no Brasil. In: Participação Popular, Educação e Saúde, Teoria e Prática (V. V. Valla \& E. N. Stotz, org.), pp. 55-86, Rio de Janeiro: Relume-Dumará.

VALLA, V. V., 1998. Sobre participação popular: Uma questão de perspectiva. Cadernos de Saúde Pública, 14(Sup. 2):7-18.

Recebido em 15 de agosto de 2001

Versão final reapresentada em 1 de fevereiro de 2002

Aprovado em 15 de março de 2002 